\title{
Exercise during school hours when added to patient education improves outcome for 2 years in adolescent patellofemoral pain: a cluster randomised trial
}

\author{
M S Rathleff, ${ }^{1,2}$ E M Roos, ${ }^{3}$ J L Olesen, ${ }^{4,5,6}$ S Rasmussen ${ }^{1,2,6}$
}

- Additional material is published online only. To view please visit the journal online (http://dx.doi.org/10.1136/ bjsports-2014-093929).

${ }^{1}$ Department of Health, Aarhus University, Aarhus, Denmark

${ }^{2}$ Orthopaedic Surgery Research Unit, Aalborg University

Hospital, Aalborg, Denmark

${ }^{3}$ Research Unit for

Musculoskeletal Function and Physiotherapy, Department of Sports Science and Clinical Biomechanics, University of Southern Denmark, Odense, Denmark

${ }^{4}$ Department of Rheumatology, Aalborg University Hospital, Aalborg, Denmark

Institute of Sports Medicine Copenhagen, Copenhagen University Hospital, Bispebjerg, Denmark

${ }^{6}$ Department of Clinical Medicine, Aalborg University, Aalborg, Denmark

\section{Correspondence to}

Dr Michael Skovdal Rathleff, Sdr Skovvej 15, Aalborg 9000, Denmark

michaelrathleff@gmail.com

Received 5 June 2014 Revised 30 September 2014 Accepted 26 October 2014 Published Online First

11 November 2014

\section{ABSTRACT}

Background Patellofemoral pain (PFP) is common among adolescents and associated with long-lasting pain and disability. Patient education and exercise therapy are commonly used treatments in primary and secondary care but the effect of these treatments in adolescents is unknown. We aimed to determine the effect of exercise therapy as an add-on therapy to patient education compared with education alone. Methods 121 adolescents from 15-19 years of age were cluster randomised to patient education or patient education combined with exercise therapy. Patient education covered self-management of pain and information on PFP. Exercise therapy consisted of supervised exercises on school premises (3/week for 3 months) and instructions on home-based exercises. Adherence to exercises was assessed as attendance and weekly text messages. Primary outcome measure was self-reported recovery (seven-point Likert scale) at 12 months with additional follow-ups at 3, 6 and 24 months.

Results Adolescents randomised to patient education and exercise therapy were more likely to have recovered at 12 months $(\mathrm{OR}, 1.73,95 \% \mathrm{Cl} 1.02$ to 2.93 , number needed to treat (NNT) of 11). Similar results were observed at 3 and 6 months (OR 1.88 and 1.43) while the effect was further increased at 24 months (OR of 2.52, NNT of 5). A higher total number of weekly exercise sessions increased the odds of recovery.

Conclusions In adolescent PFP, the addition of exercise therapy for 3 months was more effective than patient education alone. The effect was apparent at 3 months and increased up to 2 years. Adherence to exercises was important and improved the odds of recovery.

Trial registration number clinicaltrials.gov reference: NCT01438762.

\section{INTRODUCTION}

Knee pain bothers a third of adolescents and more than 50\% will at some point contact their general practitioner (GP) to seek treatment. ${ }^{1-3}$ One of the most long-lasting and troublesome conditions among adolescents with knee pain is patellofemoral pain (PFP), affecting 6-7\%. ${ }^{4-6}$ PFP is provoked by activities of daily living such as stair climbing and squatting and $25 \%$ will have significant symptoms even 16 years after treatment. ${ }^{7}{ }^{8}$ Despite the high prevalence among adolescents, the vast majority of research on treatment of PFP is conducted on adults above 18 years of age.
Exercise therapy is a cornerstone treatment for adults with PFP as it offers superior effect compared with patient education or a wait-and-see approach. ${ }^{9}{ }^{10}$ However, patient education and wait-and-see approaches are both used in general practice but only a single study has compared patient education to exercise therapy. ${ }^{10}$ It showed better outcomes at 3 and 12 months among mostly adult patients randomised to exercise therapy. ${ }^{10}$ Randomised controlled trials (RCTs) among adolescents with PFP are lacking, hampering evidencebased treatment in general practice of troubled adolescents with PFP.

The purpose of this RCT was to investigate the effect of exercise therapy as an add-on therapy to patient education compared with education alone on self-reported recovery. We hypothesised that a significantly larger proportion of adolescents randomised to patient education and exercise therapy would have recovered at 12 months.

\section{METHODS}

\section{Design overview}

The design was a cluster RCT and the study protocol has been published previously. ${ }^{11}$ A cluster was defined as a single upper secondary school. In total, 2846 adolescents between 15 and 19 years of age from four upper secondary schools were asked to answer an online questionnaire on self-reported pain (for further details on the online questionnaire refer to Rathleff et $a l^{12}$ ). Adolescents with PFP were recruited from this closed population-based cohort. $^{11}$

\section{Setting and participants}

Eligibility criteria for inclusion were in line with a previous clinical trial and determined by a rheumatologist: ${ }^{13}$ insidious onset of anterior knee or retropatellar pain of more than 6 weeks duration and provoked by at least two of the following situations: prolonged sitting or kneeling, squatting, running, hopping or stair climbing; tenderness on palpation of the patella, pain when stepping down or double leg squatting; and worst pain during the previous week of more than $30 \mathrm{~mm}$ on a $100 \mathrm{~mm}$ visual analogue scale (VAS). Exclusion criteria were concomitant injury or pain from the hip, lumbar spine or other knee structures; previous knee surgery; self-reported patellofemoral instability; knee joint effusion; use of physiotherapy for treating knee pain within the previous year; or at least weekly use of anti-inflammatory drugs. 


\section{Randomisation and interventions}

The four schools were randomised either to patient education or patient education and exercise therapy using a computergenerated sequence developed by the main investigator (MSR). Cluster randomisation was chosen to minimise the contamination between individuals, which could occur if more than one adolescent in each class were diagnosed with PFP, but randomised to different treatment groups.

\section{Patient education}

One physiotherapist delivered the patient education in the two clusters randomised to patient education alone. The standardised patient education was held one-on-one with the adolescents and their parents. It lasted for about $30 \mathrm{~min}$ and covered: pain management; how to modify physical activity using pacing and load management strategies; information on optimal knee alignment during daily tasks; and responses to questions from the adolescent or the parents. Adolescents also received this information in an eight-page leaflet, which can be found in online supplementary appendix 1 .

\section{Patient education and exercise therapy}

One of two physiotherapists delivered the exercise therapy and patient education in each cluster. The exercise therapy was based on previous trials ${ }^{14} 15$ and consisted of a combination of supervised group training sessions and unsupervised home-based exercises.

The supervised group training sessions consisted of neuromuscular training of the muscles around the foot, knee and hip, strength training for the knee and hip, patellofemoral soft tissue mobilisation, and stretching of the muscles around the hip and knee. ${ }^{11} 16$ To progressively match the exercise level to the performance level of each participant, all exercises were available in multiple levels of difficulty. ${ }^{11}$ All adolescents started with exercises at level 1 and progressed from there. The progression followed previously described rules. ${ }^{11} 17$

The unsupervised home exercises consisted of approximately 15 min of quadriceps and hip muscle retraining and stretching. Instructions were given immediately after patient education together with a five-page leaflet with pictures and descriptions of the exercises. The exercises were to be performed each day except on the days of supervised group training. ${ }^{15}$ The adolescents were instructed to incorporate the exercises into their normal daily routines. Taping corrections were applied in a predetermined order of anterior tilt, medial tilt, glide and fat pad unloading until the participant's pain was reduced by at least $50 \%{ }^{15}$ Tape was only used if adolescents achieved a minimum of $50 \%$ reduction in pain measured with a $10 \mathrm{~cm}$ VAS during a two-leg squat immediately after application of the tape. ${ }^{11}$

The supervised exercises were offered three times per week on school premises immediately after the end of the school day for 3 months (from 26 of September to 22 of December 2011, a maximum number of 41 training sessions). Exercise sessions were offered at three time points during the afternoon of each of three designated weekdays, a total of nine options weekly. The adolescents were told they should continue with the exercises on their own after the intervention period.

\section{Adherence to exercise therapy}

Adherence to the supervised sessions was recorded as attendance. Adherence to home exercises was monitored using a weekly text message that asked the adolescents "How many times during the last week did you perform your home-based exercises". Good adherence was defined as participation in at least $80 \%$ of the supervised group training sessions whereas poor adherence was defined as participation in less than $40 \%$. Good adherence of home exercises was defined as exercising on at least $70 \%$ of possible days and poor adherence was defined as exercising on less than $40 \%$ of possible days. The strategies used to optimise adherence can found in the study protocol. ${ }^{11}$

\section{Co-interventions}

Adolescents were asked to refrain from co-interventions during the intervention period starting $72 \mathrm{~h}$ before participation in the study. Pre-existing foot orthoses were allowed, but adolescents were not allowed to modify them during the study period. Analgesic use was registered during baseline testing and at all follow-ups.

\section{Outcomes and follow-up}

Self-report questionnaires were completed at baseline, 3, 6, 12 and 24 months after inclusion and collected by blinded project personnel. The primary endpoint was at 12 months. Identical to van Linschoten et al, ${ }^{10}$ the primary outcome was the proportion of adolescents recovered. The adolescents were asked to rate their knee pain now compared to before they received treatment. Recovery was measured on a seven-point Likert scale ranging from "completely recovered" to "worse than ever". Adolescents were categorised as recovered if they rated themselves as "completely recovered" or "strongly recovered" (category 1 or 2), whereas those who rated themselves as "slightly recovered" to "worse than ever" (category 3-7) were categorised as not recovered. ${ }^{10}$ Secondary outcomes included Knee injury and Osteoarthritis Outcome Score (KOOS), Physical Activity Scale (PAS), ${ }^{18}$ sports participation, EuroQol 5-dimensions (EQ-5D) ${ }^{19}$ and satisfaction with the result of treatment measured on a five-point Likert scale ranging from "highly satisfied" to "not satisfied at all".

\section{Statistical analysis}

We decided a priori to include all adolescents with PFP in the four clusters. We expected that $6 \%$ of adolescents would be diagnosed with PFP. $^{5}$ This corresponds to at least 150 adolescents with PFP, considering that approximately 2500 adolescents were expected to answer the online questionnaire. We expected $20 \%$ recovery in the patient education group, and 50\% recovery in the group receiving patient education combined with exercise therapy. ${ }^{10}{ }^{20}$ Using a power of $80 \%$, significance level of $5 \%$, within-cluster correlation of 0.015 , at least 59 adolescents were needed in each group. Using a fixed number of four clusters and equation 21 given by Hemming et $a l^{21}$ suggest the trial is feasible given the constraint of four clusters and the expected number of 150 adolescents with PFP. $^{21}$

\section{Statistical analyses}

All analyses were defined a priori and took place after the 12 months follow-up and no intermediate analyses were performed. The first author and a statistician not involved in the study performed all analyses. They were not blinded to group allocation during the analyses. Between-group comparison was analysed on an intention-to-treat basis and included all adolescents who responded to the questionnaire at that time point. The primary outcome was analysed through logistic regression for repeated measurement using robust variance estimates that adjust for within-cluster correlations within schools. ${ }^{22}$ Logistic regression was adjusted for the following baseline prognostic factors: gender and duration of symptoms and KOOS pain. 
Unadjusted estimates are also provided. A comparison of continuous data was made using linear regression and count data were analysed using Poisson regression, both using robust SEs adjusted for within-cluster correlations within schools. For the primary outcome, the number needed to treat (NNT) is given and calculated as $1 /$ risk difference. Secondary analyses included a predefined subgroup analysis investigating the association between treatment and adherence. ${ }^{11}$

\section{RESULTS}

Of the 2200 adolescents who answered the questionnaire, 610 reported knee pain and were potentially eligible for inclusion. A total of 504 adolescents were successfully contacted and asked standardised questions over the telephone. If they reported anterior knee pain with an insidious onset, as opposed to traumatic onset, they were offered a clinical examination at the local hospital by an experienced rheumatologist to determine the specific knee condition. Two hundred and four adolescents were invited to a clinical examination and 180 accepted, 8 adolescents did not show up, leaving 172 adolescents who were examined. From these, 153 were diagnosed with PFP and 122 were eligible to enter the study, and 121 adolescents agreed to participate (figure 1). Two clusters (schools) were randomised to patient education alone $(n=59)$ while two clusters $(n=62)$ were randomised to patient education and exercise therapy (see cluster-specific data on follow-up in online supplementary appendix 2). Baseline characteristics did not differ between the two groups, table 1 . From the 62 adolescents randomised to patient education and exercise therapy, 28 were offered patellar taping. Follow-up rate ranged from $73 \%$ to $91 \%$ with a $91 \%$ follow-up rate at the primary endpoint at 12 months. The intracluster correlation coefficient for the primary outcome was 0.00 at 3,6 and 12 months follow-up and 0.09 at 24-month follow-up.

\section{Primary outcome}

Adolescents randomised to patient education and exercise therapy were more likely to have recovered at 12 months (OR $1.73,95 \%$ CI 1.02 to 2.93 , NNT of 11 ). Similar results were observed at 3 months (OR 1.88, 95\% CI 1.25 to 2.81), 6 months (OR 1.43, 95\% CI 0.22 to 9.24 ) and at 24 months (OR 2.52, 95\% CI 1.65 to 3.86, NNT of 5), figure 2 .

An unadjusted analysis showed approximately the same estimates: 12 months (OR 1.51, 95\% CI 0.94 to 2.41), 3 months (OR 1.68, 95\% CI 0.93 to 3.04), 6 months (OR 1.61, 95\% CI 0.34 to 7.57 ) and 24 months (OR $2.83,95 \%$ CI 1.93 to 4.15 ).

\section{Secondary outcomes}

Overall, the secondary outcomes supported the findings of the primary outcome. Adolescents randomised to patient education and exercise therapy reported about $10 \mathrm{~mm}$ lower "worst pain last week" at all time points (table 2). The KOOS showed better,

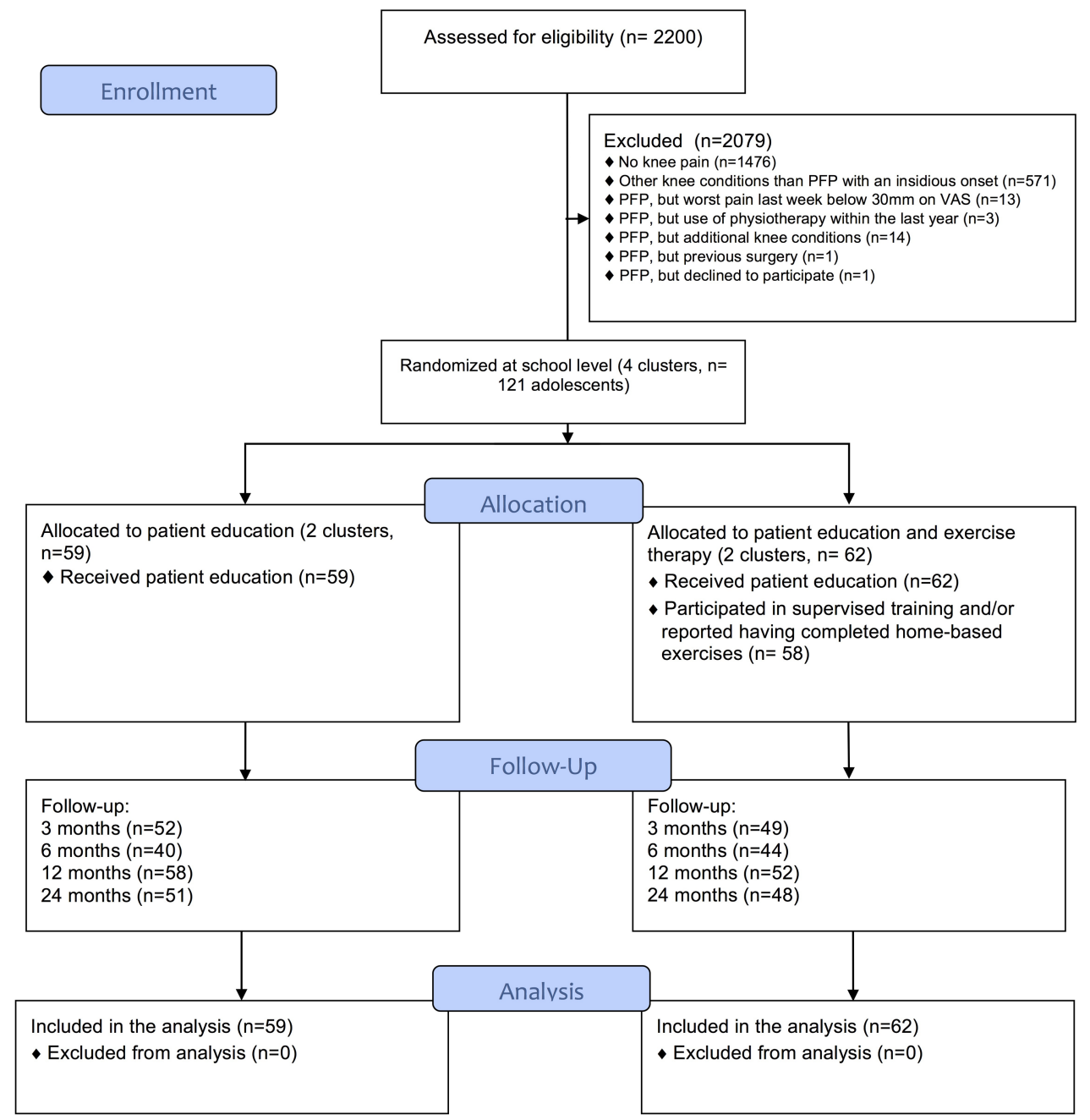

Figure 1 Flow chart (PFP, patellofemoral pain; VAS, visual analogue scale). 
though not consistently significant or clinically relevant, mean scores among the group randomised to patient education and exercise therapy, with mean between-group differences ranging from 0 to 12 points for the different subscales and time points. EQ-5D scores, PAS levels and sports participation per week were similar between groups, table 2 .

\section{Prespecified subgroup analysis based on adherence to exercise}

Adolescents randomised to patient education and exercise therapy participated in a median of 8.5 supervised training sessions (20\% of the 42 supervised training sessions possible). None had good adherence with the supervised training sessions. They performed a median of 25 home exercise sessions (36\% of the 69 possible sessions). The median total number of training sessions (supervised and home-based) was 29, corresponding to an average of 2.2 training sessions per week.

Adolescents who participated in more than $40 \%$ of the supervised training sessions had 1.08 (95\% CI 0.96 to 1.22$)$ times higher odds of having recovered at 12 months compared with those participating in less than $40 \%$. Adolescents with good adherence to home exercises ( $>70 \%$ of possible number of days) had 4.04 higher odds (95\% CI 1.42 to 11.55 ) of having recovered at 12 months. Performing exercise therapy 1-2 times weekly at home increased the OR to 1.47 (95\% CI 0.57 to $3.75)$ compared to those with an average of $0-1$ weekly sessions. For those exercising at home 2-3 times weekly, the OR was further increased to 2.10 (95\% CI 0.15 to 28.71) and for those performing the exercises at home a minimum of 3 times per week the OR was 4.48 (95\% CI 2.79; 7.21; figure 3).

The combined number of supervised and home exercises per week did not show the same strong dose-response relationship OR 2.00 (95\% CI 1.6 to 2.49) for $1-2$ vs $0-1$ sessions per week, OR 1.2 (95\% CI 0.05 to 30.12 ) for $2-3$ sessions per week and OR 2.6 (95\% CI 0.45 to 15.05$)$ for more than 3 sessions per week.

\section{Co-interventions and satisfaction}

Adolescents randomised to patient education and exercise therapy were more likely to be satisfied with the results of the treatment. They were also less likely to use medication at 3 and 6 months, and less likely to use other therapies at 3,12 and 24 months (table 3).
Table 1 Baseline characteristics

\begin{tabular}{|c|c|c|c|}
\hline & $\begin{array}{l}\text { Patient } \\
\text { education } \\
(n=59)\end{array}$ & $\begin{array}{l}\text { Patient education } \\
\text { and exercise } \\
\text { therapy }(n=62)\end{array}$ & All $(n=121)$ \\
\hline Age & $17.3(0.9)$ & $17.2(1.1)$ & $17.2(1.0)$ \\
\hline Gender ( $\%$ females) & 86 & 74 & 80 \\
\hline Weight $(\mathrm{kg})$ & $66.5(12.8)$ & $63.0(11.3)$ & $64.7(12.1)$ \\
\hline Height $(\mathrm{cm})$ & $171.7(8.3)$ & $172.2(9.1)$ & $172.0(8.7)$ \\
\hline $\mathrm{BMI}$ & $22.4(3.1)$ & $21.1(2.5)$ & $21.7(2.9)$ \\
\hline \multicolumn{4}{|c|}{ Duration of symptoms (n) (months) } \\
\hline $2-6$ & 1 & 5 & 6 \\
\hline $6-12$ & 5 & 5 & 10 \\
\hline$>12$ & 53 & 52 & 105 \\
\hline $\begin{array}{l}\text { Average pain duration } \\
\text { (months)* }\end{array}$ & $39(24 ; 63)$ & $36(18 ; 51)$ & $39(21 ; 60)$ \\
\hline Bilateral PFP (\% yes) & 80 & 77 & 79 \\
\hline $\begin{array}{l}\text { Sports participation (\% } \\
\text { participation in leisure } \\
\text { time sports) }\end{array}$ & 32 & 34 & 33 \\
\hline $\begin{array}{l}\text { Number of times per } \\
\text { week for those involved } \\
\text { in leisure time sports }\end{array}$ & $3(2 ; 4)$ & $3(2 ; 4)$ & $3(2 ; 4)$ \\
\hline $\begin{array}{l}\text { Previously treated for } \\
\text { PFP (\%) }\end{array}$ & 32 & 23 & 28 \\
\hline $\begin{array}{l}\text { Pre-existing foot } \\
\text { orthoses }(n)\end{array}$ & 2 & 2 & 4 \\
\hline $\begin{array}{l}\text { Pain medication for knee } \\
\text { pain (\% who replied } \\
\text { yes) }\end{array}$ & 19 & 24 & 21 \\
\hline $\begin{array}{l}\text { Pain at rest (visual } \\
\text { analogue scale)* }\end{array}$ & $15(4 ; 29)$ & $9(2 ; 22)$ & $13(3 ; 27)$ \\
\hline $\begin{array}{l}\text { Pain during activity } \\
\text { (visual analogue scale)* }\end{array}$ & $52(34 ; 67)$ & $50(35 ; 64)$ & $50(35 ; 64)$ \\
\hline $\begin{array}{l}\text { Worst pain last week } \\
\text { (visual analogue scale)* }^{*}\end{array}$ & $47(33 ; 69)$ & $48(34 ; 64)$ & $48(34 ; 65)$ \\
\hline
\end{tabular}

\section{DISCUSSION}

This is the first study investigating the effect of patient education and exercise therapy among adolescents with PFP. The study shows that adolescents randomised to patient education and exercise therapy were more likely to have recovered at all time
Figure 2 Primary outcome: self-reported recovery. An OR above 1.0 indicates that the odds of being recovered are higher among adolescents randomised to patient education and exercise therapy.

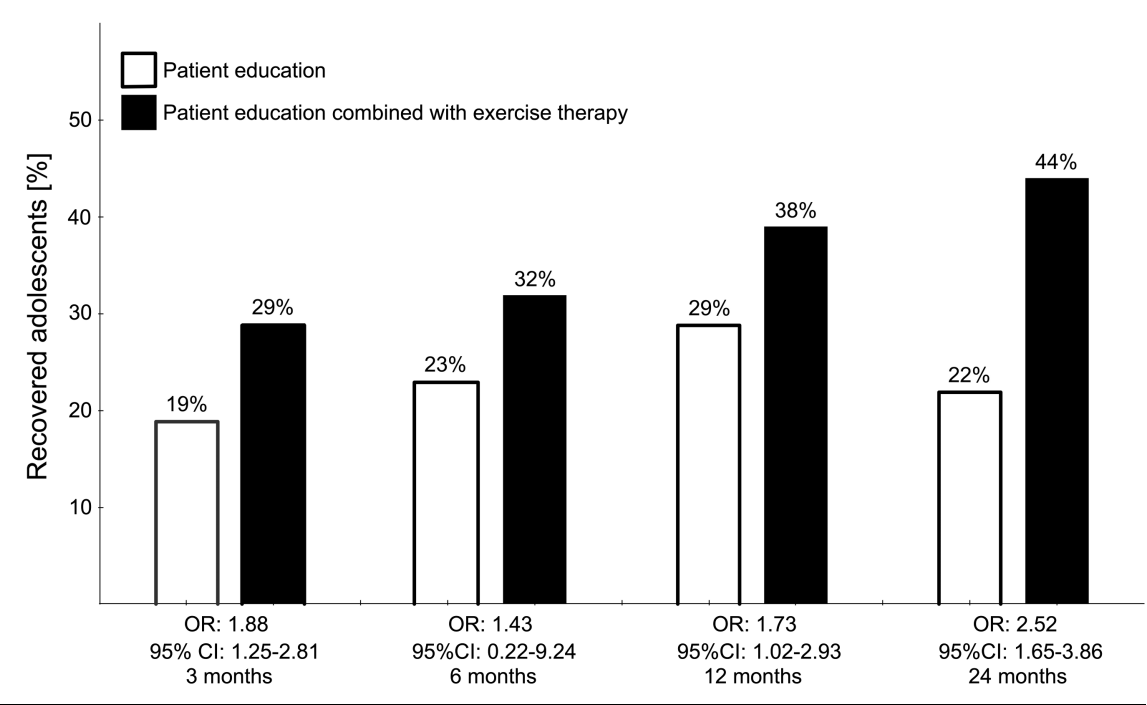

Rathleff MS, et al. Br J Sports Med 2015;49:406-412. doi:10.1136/bjsports-2014-093929 
Table 2 Mean and $95 \% \mathrm{Cl}$ of secondary outcomes including the adjusted mean difference between groups

\begin{tabular}{|c|c|c|c|}
\hline Outcome & $\begin{array}{l}\text { Patient } \\
\text { education } \\
(n=59)\end{array}$ & $\begin{array}{l}\text { Patient } \\
\text { education and } \\
\text { exercise therapy } \\
(n=62)\end{array}$ & $\begin{array}{l}\text { Adjusted mean } \\
\text { difference between } \\
\text { groups ( } 95 \% \mathrm{Cl})\end{array}$ \\
\hline \multicolumn{4}{|c|}{ Worst pain last week (mm) (months) } \\
\hline 3 & $51(44 ; 58)$ & $40(24 ; 56)$ & $-11(-30$ to 9$)$ \\
\hline 6 & $51(31 ; 70)$ & $41(21 ; 60)$ & $-10(-38$ to 19$)$ \\
\hline 12 & $49(45 ; 53)$ & $37(34 ; 39)$ & $-11(-18$ to 5$)$ \\
\hline 24 & $35(1 ; 69)$ & $24(15 ; 33)$ & $-11(-46$ to 25$)$ \\
\hline \multicolumn{4}{|c|}{$\mathrm{KOOS}_{\text {pain }}(0-100$, worst to best) (months) } \\
\hline 3 & $71(67 ; 74)$ & $78(76 ; 81)$ & $4(-2$ to 11$)$ \\
\hline 6 & $74(74 ; 75)$ & $79(76 ; 82)$ & $2(-6$ to 9$)$ \\
\hline 12 & $73(70 ; 76)$ & $79(79 ; 80)$ & $3(0 \text { to } 6)^{*}$ \\
\hline 24 & $73(61 ; 84)$ & $85(84 ; 85)$ & $10(3 \text { to } 17)^{*}$ \\
\hline \multicolumn{4}{|c|}{$\mathrm{KOOS}_{\text {symptoms }}(0-100$, worst to best) (months) } \\
\hline 3 & $79(75 ; 80)$ & $84(82 ; 86)$ & $3(2 \text { to } 4)^{*}$ \\
\hline 6 & $80(73 ; 85)$ & $82(74 ; 89)$ & $0(-9$ to 9$)$ \\
\hline 12 & $77(77 ; 78)$ & $83(81 ; 85)$ & $2(-2$ to 5$)$ \\
\hline 24 & $76(67 ; 86)$ & $84(81 ; 87)$ & $7(-4$ to 19$)$ \\
\hline \multicolumn{4}{|c|}{$\mathrm{KOOS}_{\mathrm{ADL}}$ (0-100, worst to best) (months) } \\
\hline 3 & $81(79 ; 82)$ & $89(89 ; 89)$ & $5(-1$ to 11$)$ \\
\hline 6 & $84(83 ; 85)$ & $90(87 ; 92)$ & $3(-3$ to 9$)$ \\
\hline 12 & $83(82 ; 83)$ & $89(88 ; 90)$ & $3(0 \text { to } 6)^{*}$ \\
\hline 24 & $83(75 ; 91)$ & $91(90 ; 92)$ & $6(1 \text { to } 12)^{*}$ \\
\hline \multicolumn{4}{|c|}{$\mathrm{KOOS}_{\text {sport/rec }}(0-100$, worst to best) (months) } \\
\hline 3 & $58(53 ; 62)$ & $68(64 ; 73)$ & $6(-4$ to 16$)$ \\
\hline 6 & $61(60 ; 61)$ & $71(60 ; 82)$ & $5(-13$ to 22$)$ \\
\hline 12 & $58(51 ; 65)$ & $70(64 ; 77)$ & $7(-7$ to 20$)$ \\
\hline 24 & $62(43 ; 80)$ & $75(68 ; 82)$ & $10(-7$ to 28$)$ \\
\hline \multicolumn{4}{|c|}{$\mathrm{KOOS}_{\mathrm{QOL}}(0-100$, worst to best) } \\
\hline 3 & $54(52 ; 57)$ & $62(54 ; 71)$ & $6(-5$ to 16$)$ \\
\hline 6 & $58(56 ; 59)$ & $63(52 ; 75)$ & $4(-9$ to 18$)$ \\
\hline 12 & $59(59 ; 60)$ & $65(63 ; 67)$ & $4(1 \text { to } 6)^{*}$ \\
\hline 24 & $58(47 ; 69)$ & $71(65 ; 78)$ & $12(0 \text { to } 25)^{*}$ \\
\hline \multicolumn{4}{|c|}{ Sport sessions per weekt (times per week) (months) } \\
\hline 3 & $1(0 ; 2.5)$ & $1(0 ; 3)$ & $0.07(-0.19$ to 0.34$) \ddagger$ \\
\hline 6 & $2(0 ; 3)$ & $1(0 ; 2.5)$ & $-0.19(-0.44$ to 0.06$) \ddagger$ \\
\hline 12 & $2(0 ; 3)$ & $1.5(0 ; 3)$ & $-0.11(-0.63$ to 0.41$) \ddagger$ \\
\hline 24 & $1(0-2)$ & $1.5(0 ; 2.5)$ & $0.31(-0.19$ to 0.81$) \ddagger$ \\
\hline \multicolumn{4}{|c|}{ PASt (metabolic equivalent) (months) } \\
\hline 3 & $46.4(45.7 ; 47.0)$ & $44.6(42.2 ; 47.1)$ & $-1.8(-3.7$ to 0.2$)$ \\
\hline 6 & $47.5(41.3 ; 53.7)$ & $45.6(44.9 ; 46.4)$ & $-2.4(-7.0$ to 2.1$)$ \\
\hline 12 & $47.6(44.6 ; 50.6)$ & $47.9(45.3 ; 50.4)$ & $0.0(-4.3$ to 4.2$)$ \\
\hline 24 & $47.6(43.7 ; 52.7)$ & $46.3(37.2 ; 51.4)$ & $-2.5(-6.3$ to 1.3$)$ \\
\hline \multicolumn{4}{|c|}{ EQ-5D† (index score) (months) } \\
\hline 3 & $0.78(0.72 ; 0.82)$ & $0.78(0.78 ; 1.00)$ & $0.04(-0.03$ to 0.12$) \ddagger$ \\
\hline 6 & $0.76(0.66 ; 0.82)$ & $0.82(0.72 ; 0.84)$ & $0.00(-0.12$ to 0.12$) \ddagger$ \\
\hline 12 & $0.78(0.72 ; 0.82)$ & $0.82(0.77 ; 1.00)$ & $0.03(-0.09$ to 0.14$) \ddagger$ \\
\hline 24 & $0.82(0.72 ; 0.84)$ & $0.82(0.78 ; 1.00)$ & $0.05(-0.01$ to 0.11$) \ddagger$ \\
\hline \multicolumn{4}{|c|}{$\begin{array}{l}\text { * }<0.05 \text {. } \\
+ \text { Median and IQR. } \\
\text { ¥Coefficients from Poisson regression. The value is the expected increase in log count } \\
\text { for the group randomised to exercise therapy and patient education compared to the } \\
\text { group randomised to patient education alone. } \\
\text { EQ-5D, EuroQol 5-dimensions; KOOS, Knee injury and Osteoarthritis Outcome Score; } \\
\text { PAS, Physical Activity Scale. }\end{array}$} \\
\hline
\end{tabular}

points compared with those receiving patient education alone. This study adds evidence-based knowledge about treatment of adolescent PFP in general practice and suggest that exercise therapy is effective and adherence is important for recovery.

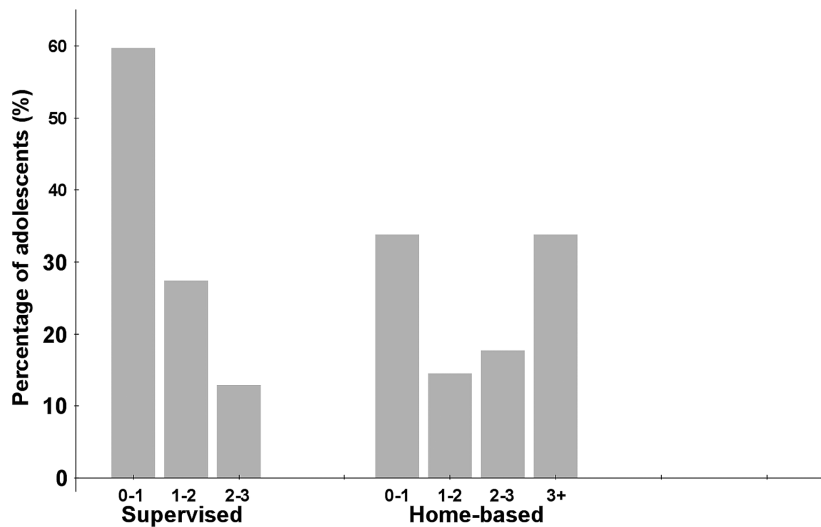

Figure 3 Adherence with supervised and home-based exercises. The grey bars showing the percentage of adolescents who participated in an average of $0-1,1-2,2-3$ or more than three supervised or home-based exercises per week.

\section{Comparison to previous studies}

The latest systematic review covering conservative treatment of PFP in adults shows strong evidence that exercise therapy is more effective than placebo treatment. ${ }^{9}$ Even though PFP is common among adolescents, ${ }^{5} 23$ only one small randomised trial has been conducted among adolescents. ${ }^{24}$ Eng and Pierrynowski ${ }^{24}$ recruited 20 adolescent females with excessive forefoot varus or calcaneal valgus. They found that a combination of exercises and orthoses resulted in larger reductions in pain after 8 weeks compared with exercise alone. This may point towards an additive effect of exercises and orthoses among the subgroup of adolescents with excessive forefoot varus or calcaneal valgus. van Linschoten $e t a l^{10}$ compared exercise therapy to usual care. They, however, included a mixed-age group, with the majority being above 18 years of age. Usual care was similar to the patient education used in our study. van

Table 3 Proportions and OR for a comparison of the use of medication, other therapies and satisfaction with the result of treatment

\begin{tabular}{|c|c|c|c|}
\hline Outcome & $\begin{array}{l}\text { Patient } \\
\text { education } \\
(n=59)\end{array}$ & $\begin{array}{l}\text { Patient education and } \\
\text { exercise therapy }(n=62)\end{array}$ & $\mathrm{OR}(95 \% \mathrm{Cl})^{*}$ \\
\hline \multicolumn{4}{|c|}{ Medication (\% who replied yes) (months) } \\
\hline 3 & 23 & 18 & $0.8(0.7$ to 0.8$)$ \\
\hline 6 & 30 & 16 & $0.4(0.3$ to 0.6$)$ \\
\hline 12 & 29 & 31 & $1.1(0.5$ to 2.4$)$ \\
\hline 24 & 18 & 13 & $0.7(0.3$ to 1.5$)$ \\
\hline
\end{tabular}

Other therapies (additional physiotherapy, orthoses, acupuncture) (\% who replied yes) (months)

$\begin{array}{llll}3 & 19 & 16 & 0.8(0.7 \text { to } 0.9) \\ 6 & 21 & 19 & 0.9(0.5 \text { to } 1.5) \\ 12 & 34 & 20 & 0.5(0.3 \text { to } 0.8) \\ 24 & 33 & 10 & 0.2(0.1 \text { to } 0.5)\end{array}$

Satisfaction with the result of the treatment (\% who replied 1 or 2 on the five-point Likert scale) (months)

$\begin{array}{llll}3 & 19 & 51 & 4.4(1.8 \text { to } 10.8) \\ 6 & 35 & 57 & 2.4(1.1 \text { to } 5.5) \\ 12 & 36 & 60 & 2.6(2.4 \text { to } 2.8) \\ 24 & 22 & 44 & 2.8(1.4 \text { to } 5.3)\end{array}$

* Odds below 1.0 indicate the group randomised to patient education and exercise therapy being less likely to use medication or other therapies. 
Linschoten et $\mathrm{al}^{10}$ found a recovery rate of $62 \%$ in the exercise group and $51 \%$ in the usual care group corresponding to adjusted odds for recovery of 1.60 at 12 months. That OR is similar to ours (OR of 1.73 , their $\mathrm{NNT}=9$, our $\mathrm{NNT}=11$ ); however, their proportion of recovered participants $(62 \%)$ was much larger than ours (38\%).

In the study by Collins et $a l,{ }^{25}$ only participants aged 18 and older were included. At 12 months follow-up, the proportion of participants who reported moderate or marked improvement (similar to the primary outcome in the current RCT) was $81 \%$ in the group receiving exercise therapy only. The proportion of recovered adolescents in our trial compared with previous trials suggests that patient education and exercise therapy may be slightly less effective in adolescents compared with adults. One of the reasons may be the long symptom duration. Previous studies show that a long symptom duration ${ }^{26} 27$ is associated with worse outcome and only $5 \%$ of the adolescents reported a symptom duration below 6 months. This is a longer symptom duration compared with previous trials on adults. van Linschoten et $a l^{10}$ reported that almost $70 \%$ of their patients had a symptom duration between 2 and 6 months, while the median symptom duration reported by Collins et $a l^{25}$ was 28 months with only $25 \%$ having a symptom duration below 12 months. Future studies might consider intervening even earlier.

\section{Explanation of results}

The dose-response association between adherence to home exercises and recovery would suggest that adherence is highly important and that the more often home exercises are performed, the greater the odds of recovery. Before starting the study, we expected that adherence would be a challenge and introduced several strategies to increase adherence. Despite this, adherence to supervised exercise in particular was low. However, overall, adolescents exercised on average 2.2 times per week, which is similar to what was observed in previous trials on exercise for adults with PFP. ${ }^{10} 2528$ This suggests that home exercise, performed after attending a patient education session and receiving thorough instructions from a physical therapist, and with weekly SMS reminders, is a viable treatment option for adolescent PFP.

\section{Strengths and weaknesses of the study}

Owing to the study design and recruitment procedure, the sample size was fixed in advance. Because recruitment took place from a population-based cohort, a cluster RCT seemed a better design compared with randomisation at subject level. However, we were limited to four clusters, which reduced the benefits of the randomised design. Randomisation at subject level could have introduced a high risk of contamination if two adolescents in one class were allocated to two different interventions. ${ }^{29}$

Our primary outcome was self-reported recovery. Self-reported recovery does not itemise in which domain the adolescent has recovered. In support, our secondary outcomes pointed towards greater improvements in more specific domains such as self-reported KOOS pain, ADL, function and sport, quality of life as well as satisfaction with the result of treatment, which all are of great relevance for our patient group.

A significant strength is that all adolescents were recruited from a population-based cohort and only one eligible adolescent did not want to participate. Recruiting from a population-based cohort is very relevant for adolescents, as those with an insidious onset of knee pain (such as PFP) are less likely to contact their GPs compared with adolescents with knee pain of traumatic onset. ${ }^{1}$ This suggests that the study results have a very high external validity and are generalisable to the adolescent population between 15 and 19 years. Further, the internal validity is increased by recruitment of all adolescents at one time point and conducting follow-ups within the same time period of the year.

\section{Clinical implications}

This study points to an effective evidence-based treatment option for adolescents with PFP, a troubled group of patients commonly seen in general practice. The GP can with confidence refer the patient to a physiotherapist to learn the exercises needed. The patient can perform the exercises at home, or under supervision of the physiotherapist, whichever option promotes a high adherence to the exercises. Our use of a predefined set of simple guidelines ${ }^{11}$ for determining when to reduce and when to add to the exercises will help individualise and replicate the exercise programme in clinical practice.

\section{Future research}

This trial highlighted the importance of adherence. Future studies should consider strategies that can improve adherence. Within the large group of adolescents with PFP there might be subgroups of adolescents who respond better to specific treatments. It may be that adolescents with a very high activity level may respond better to activity modification for a short period of time. Likewise, adolescents with poor adherence and no interest in exercises would benefit more from foot orthoses. If these subgroups exist it may be an option to improve recovery rates.

\section{CONCLUSION}

In adolescent PFP, the addition of exercise therapy for 3 months was more effective than patient education alone. The effect was apparent even at 3 months and increased up until 2 years. Adherence to exercises was important and improved the odds of recovery.

\section{What are the new findings}

- At all time points (3-24 months), exercise therapy and patient education were more effective than patient education alone on self-reported recovery among adolescents with patellofemoral pain.

- After 24 months, $44 \%$ had recovered among those randomised to patient education and exercise therapy while only $22 \%$ had recovered among those randomised to patient education.

- There was a positive dose-response relationship between exercise and recovery, suggesting at least two weekly home-based sessions are needed and more exercise is even better.

\section{Impact on clinical practice in the near future}

- An evidence-based treatment can now be offered to adolescents with patellofemoral pain.

- The physician can with confidence refer adolescents with patellofemoral pain to a physiotherapist teaching the patient the exercises needed.

- General practitioners and physicians should be aware that adolescent patellofemoral pain is a serious knee condition and significant proportions of patients continue to have pain even after 2 years. 
Acknowledgements Senior statistician Professor Martin Bøgsted is acknowledged for his help with data analyses. The authors acknowledge Camilla Rams Rathleff, physiotherapist; Niels Balslev, physiotherapist; Josephine Nielsen, MSc; Birgitte Hede Christensen, MSc; Kathrine Skov Andersen, MSc; Lise Jensen, physiotherapist; Mads Nyhus Rasch, MD; and Sune Kjems Skuldbøl, MD, for their help in collecting data and handling logistics. Furthermore, they are grateful to the schools in the Municipality of Aalborg, which helped them conduct this study.

Contributors All authors made substantial scientific contributions to the design of the trial. MSR wrote the first draft for this manuscript. EMR, JLO and SR all made valuable scientific additions to the draft. All authors read and approved the final manuscript. MSR and SR took responsibility for the study from inception to report and acted as guarantors. MSR and SR affirm that the manuscript is an honest, accurate and transparent account of the study being reported and that no important aspects of the study have been omitted and that any discrepancies from the study as planned have been explained.

Funding The study is being funded by the Danish Rheumatism Association, The Association of Danish Physiotherapists Research Fund and The Obelske Family Foundation. MSR is being funded by a full-time PhD scholarship from the Graduate School of Health Sciences at Aarhus University.

Competing interests None.

Ethics approval The trial was conducted in accordance with Good Clinical Practice guidelines, the Declaration of Helsinki, the Clinical Trials Regulations and local laws and regulations. Ethical approval was obtained from the local ethics committee in the North Denmark Region (N-20110020) and the trial was registered at clinical trials (NCT01438762).

Provenance and peer review Not commissioned; externally peer reviewed.

Data sharing statement All data can be retrieved by e-mailing the first author.

\section{REFERENCES}

1 Rathleff MS, Skuldbol SK, Rasch MN, et al. Care-seeking behaviour of adolescents with knee pain: a population-based study among 504 adolescents. BMC Musculoskelet Disord 2013;14:225.

2 Fairbank JC, Pynsent PB, van Poortvliet JA, et al. Mechanical factors in the incidence of knee pain in adolescents and young adults. J Bone Joint Surg Br 1984;66:685-93.

3 Stovitz SD, Pardee PE, Vazquez G, et al. Musculoskeletal pain in obese children and adolescents. Acta Paediatr 2008:97:489-93.

4 Rathleff MS, Roos EM, Olesen JL, et al. Lower mechanical pressure pain thresholds in female adolescents with patellofemoral pain syndrome. J Orthop Sports Phys Ther 2013;43:414-21

5 Molgaard C, Rathleff MS, Simonsen 0. Patellofemoral pain syndrome and its association with hip, ankle, and foot function in 16- to 18-year-old high school students: a single-blind case-control study. J Am Podiatr Med Assoc 2011;101:215-22.

6 Witvrouw E, Callaghan MJ, Stefanik JJ, et al. Patellofemoral pain: consensus statement from the 3rd International Patellofemoral Pain Research Retreat held in Vancouver, September 2013. Br J Sports Med 2014;48:411-14.

7 Haim A, Yaniv M, Dekel $S$, et al. Patellofemoral pain syndrome: validity of clinica and radiological features. Clin Orthop Relat Res 2006;451:223-8.

8 Nimon G, Murray D, Sandow M, et al. Natural history of anterior knee pain: a 14- to 20-year follow-up of nonoperative management. J Pediatr Orthop 1998;18:118-22.

9 Collins NJ, Bisset LM, Crossley KM, et al. Efficacy of nonsurgical interventions for anterior knee pain: systematic review and meta-analysis of randomized trials. Sports Med 2012:42:31-49.
10 van Linschoten $\mathrm{R}$, van Middelkoop M, Berger MY, et al. Supervised exercise therapy versus usual care for patellofemoral pain syndrome: an open label randomised controlled trial. BMJ 2009;339:b4074.

11 Rathleff MS, Roos EM, Olesen JL, et al. Early intervention for adolescents with patellofemoral pain syndrome-a pragmatic cluster randomised controlled trial. BMC Musculoskelet Dis 2012:13:9.

12 Rathleff MS, Roos EM, Olesen JL, et al. High prevalence of daily and multi-site pain - a cross-sectional population-based study among 3000 Danish adolescents. BMC Pediatr 2013:13:191.

13 Crossley K, Bennell K, Green S, et al. Physical therapy for patellofemoral pain: a randomized, double-blinded, placebo-controlled trial. Am J Sports Med 2002;30:857-65.

14 Crossley KM, Vicenzino B, Pandy MG, et al. Targeted physiotherapy for patellofemoral joint osteoarthritis: a protocol for a randomised, single-blind controlled trial. BMC Musculoskelet Dis 2008:9:122.

15 Crossley K, Bennell K, Green S, et al. Physical therapy for patellofemoral pain-a randomized, double-blinded, placebo-controlled trial. Am J Sports Med 2002;30:857-65

16 Rathleff MS, Rathleff CR, Crossley KM, et al. Is hip strength a risk factor for patellofemoral pain? A systematic review and meta-analysis. Br J Sports Med 2014;48:1088.

17 Ageberg E, Link A, Roos EM. Feasibility of neuromuscular training in patients with severe hip or knee OA: the individualized goal-based NEMEX-TJR training program. BMC Musculoskelet Dis 2010;11:126.

18 Aadahl M, Jorgensen T. Validation of a new self-report instrument for measuring physical activity. Med Sci Sports Exerc 2003:35:1196-202.

19 Rabin R, de Charro F. EQ-5D: a measure of health status from the EuroQol group. Ann Med 2001:33:337-43.

20 Clark DI, Downing N, Mitchell J, et al. Physiotherapy for anterior knee pain: a randomised controlled trial. Ann Rheum Dis 2000;59:700-4.

21 Hemming K, Girling AJ, Sitch AJ, et al. Sample size calculations for cluster randomised controlled trials with a fixed number of clusters. BMC Med Res Methodol 2011:11:102.

22 Williams RL. A note on robust variance estimation for cluster-correlated data. Biometrics 2000:56:645-6.

23 Rathleff MS, Samani A, Olesen JL, et al. Neuromuscular activity and knee kinematics in adolescents with patellofemoral pain. Med Sci Sports Exer 2013;45:1730-9.

24 Eng JJ, Pierrynowski MR. Evaluation of soft foot orthotics in the treatment of patellofemoral pain syndrome. Phys Ther 1993;73:62-8; discussion 68-70.

25 Collins N, Crossley K, Beller E, et al. Foot orthoses and physiotherapy in the treatment of patellofemoral pain syndrome: randomised clinical trial. $B M J$ 2008;337:a1735.

26 Collins NJ, Crossley KM, Darnell R, et al. Predictors of short and long term outcome in patellofemoral pain syndrome: a prospective longitudinal study. BMC Musculoskelet Dis 2010;11:11.

27 Blond L, Hansen L. Patellofemoral pain syndrome in athletes: a 5.7-year retrospective follow-up study of 250 athletes. Acta Orthop Belg 1998. 64:393-400.

28 Dolak KL, Silkman C, Medina McKeon J, et al. Hip strengthening prior to functional exercises reduces pain sooner than quadriceps strengthening in females with patellofemoral pain syndrome: a randomized clinical trial. J Orthop Sports Phys Ther 2011:41:560-70

29 Slymen DJ, Hovell MF. Cluster versus individual randomization in adolescent tobacco and alcohol studies: illustrations for design decisions. Int J Epidemiol 1997;26:765-71 